Atmos. Chem. Phys., 13, 2223-2233, 2013

www.atmos-chem-phys.net/13/2223/2013/

doi:10.5194/acp-13-2223-2013

(C) Author(s) 2013. CC Attribution 3.0 License.

\title{
Collision dynamics and uptake of water on alcohol-covered ice
}

\author{
E. S. Thomson ${ }^{1}$, X. Kong ${ }^{1}$, N. Marković ${ }^{2}$, P. Papagiannakopoulos ${ }^{1,3}$, and J. B. C. Pettersson ${ }^{1}$ \\ ${ }^{1}$ Department of Chemistry and Molecular Biology, Atmospheric Science, University of Gothenburg, 412 96, Gothenburg, \\ Sweden \\ ${ }^{2}$ Department of Chemical and Biological Engineering, Physical Chemistry, Chalmers University of Technology, 41296 , \\ Gothenburg, Sweden \\ ${ }^{3}$ Laboratory of Photochemistry and Kinetics, Department of Chemistry, University of Crete, 71003 Heraklion, Crete, Greece \\ Correspondence to: E. S. Thomson (erik.thomson@chem.gu.se) and J. B. C. Pettersson (janp@chem.gu.se)
}

Received: 8 October 2012 - Published in Atmos. Chem. Phys. Discuss.: 22 October 2012

Revised: 2 February 2013 - Accepted: 11 February 2013 - Published: 25 February 2013

\begin{abstract}
Molecular scattering experiments are used to investigate water interactions with methanol and n-butanol covered ice between $155 \mathrm{~K}$ and $200 \mathrm{~K}$. The inelastically scattered and desorbed products of an incident molecular beam are measured and analyzed to illuminate molecular scale processes. The residence time and uptake coefficients of water impinging on alcohol-covered ice are calculated. The surfactant molecules are observed to affect water transport to and from the ice surface in a manner that is related to the number of carbon atoms they contain. Butanol films on ice are observed to reduce water uptake by $20 \%$, whereas methanol monolayers pose no significant barrier to water transport. Water colliding with methanol covered ice rapidly permeates the alcohol layer, but on butanol water molecules have mean surface lifetimes of $\lesssim 0.6 \mathrm{~ms}$, enabling some molecules to thermally desorb before reaching the water ice underlying the butanol. These observations are put into the context of cloud and atmospheric scale processes, where such surfactant layers may affect a range of aerosol processes, and thus have implications for cloud evolution, the global water cycle, and long term climate.
\end{abstract}

\section{Introduction}

In the upper troposphere cirrus ice clouds play a disproportionately large role, compared to their diminutive thickness, on the radiative balance of Earth. This is due to their low temperatures and tendency to be more opaque to the long wave radiation emitted by the surface of the Earth, than to the incoming short wave radiation from the sun. Ice and cloud pa- rameterizations provide important input into global climate models (Hoose et al., 2010), yet at these altitudes underlying fundamental processes remain difficult to study. Advances in remote sensing have allowed for sophisticated monitoring (Comstock et al., 2008) and large spatial studies (Eliasson et al., 2011) but the remoteness and temperature and pressure regimes of ice clouds make them difficult to access in the field and to simulate in the laboratory. While many cloud processes are becoming better understood, the scientific uncertainty associated with clouds contributes a high degree of ambiguity to a complete understanding of the global climate system (Solomon et al., 2007), that is further complicated by the chemical and physical heterogeneity of ice clouds at a range of scales (Bartels-Rausch et al., 2012).

Surface-active organics are one ubiquitous example of common atmospheric constituents that affect aerosol particles, water droplets and ice particles. A principal characteristic of organic surfactant molecules in the atmosphere is that they possess both water-repelling and water-attracting structures which make them surface active. The activation and cloud forming potential of atmospheric aerosols is affected by scavenging and aging indicative of organic components (Hallquist et al., 2009). Likewise surface-active organic compounds are known to influence water adsorption and desorption on cloud particles (Park et al., 2009; Hudson et al., 2002). In the extreme, surfactants may altogether prevent transport between gaseous phase molecules and aerosol particles (cf. Barnes, 2008). In cirrus clouds molecular surfactants, like volatile organic compounds (VOCs), can also affect ice nucleation efficiency and rate, growth morphology and even nucleation mode (Murray and Bertram, 2008; 
Möhler et al., 2005). Thus properties from cloud lifetime, to cloud thickness and height, and radiative properties may all be affected by changing the surface properties of ice seeds. In addition to direct chemical and radiative effects, changing cloud particle size and lifetime could have broader consequences for tropospheric and stratospheric chemistry, and the water cycle.

Alcohols are simple VOCs and one interesting subset of organic surfactants that are widely found in the atmosphere (Singh et al., 1995), where they may be stabilized by hydrogen bond interactions with water surfaces. Their properties as surface-active compounds on substrates (Morishige and Sakamoto, 1995), including ice (Sokolov and Abbatt, 2002) have been shown to depend on molecular size in analogy to their miscibility in liquid water, which shifts significantly as their chain length is increased (Stephenson et al., 1984).

This study focuses on two hydrocarbons, methanol $\left(\mathrm{CH}_{3} \mathrm{OH}\right)$ and n-butanol $\left(\mathrm{C}_{4} \mathrm{H}_{9} \mathrm{OH}\right)$, and their effect on ice surfaces at temperatures between 155 and $200 \mathrm{~K}$. The simplicity and close resemblance of methanol to water has led to much scientific attention on their solid and liquid interactions. Commonly methanol is considered to be completely miscible in water, but observations that the entropy increase due to mixing methanol and water is less than expected for ideal solutions suggests incomplete mixing on a molecular scale (Dixit et al., 2002). Numerical simulations (Dougan et al., 2004; Morrone et al., 2006) and analysis of careful measurements (Guo et al., 2003; Soper et al., 2006) reveal networks of enhanced structure built from hydrogen-bonded water and methanol. Ultimately the behavior of methanol in water and on water surfaces depends sensitively on the balance between the molecules hydroxyl group which can participate in hydrogen bonding and its hydrophobic methyl group (Souda et al., 2003) and the specific topology of molecular level structuring (Morrone et al., 2006). Studies, specific to methanol layers on ice surfaces have observed stable monolayer coverages (Winkler et al., 2002; Jedlovszky et al., 2006). Jedlovszky et al. (2006) record isotherms that are consistent with Monte Carlo simulations, which show a monomolecular saturated adsorption layer of methanol on ice.

Butanol is a short chain n-alcohol. For more than $40 \mathrm{yr}$ it has been known that long chain alcohol layers on water reduce evaporation rates (La Mer et al., 1964; Barnes, 1997) and recently an analogous but less intense effect has been shown for butanol, both experimentally (Kong et al., 2012) and using molecular dynamical simulations (Gilde et al., 2009). However, other experiments on the evaporation of supercooled sulfuric acid droplets through butanol films show little to no effect of the butanol (Park et al., 2009; Lawrence et al., 2005). On the other hand the same studies show that butanol films enhance $\mathrm{HCl}$ uptake into the acid. These differing results suggest that the chemical and physical properties of the ice/vapour interface are quite sensitive to butanol coatings.

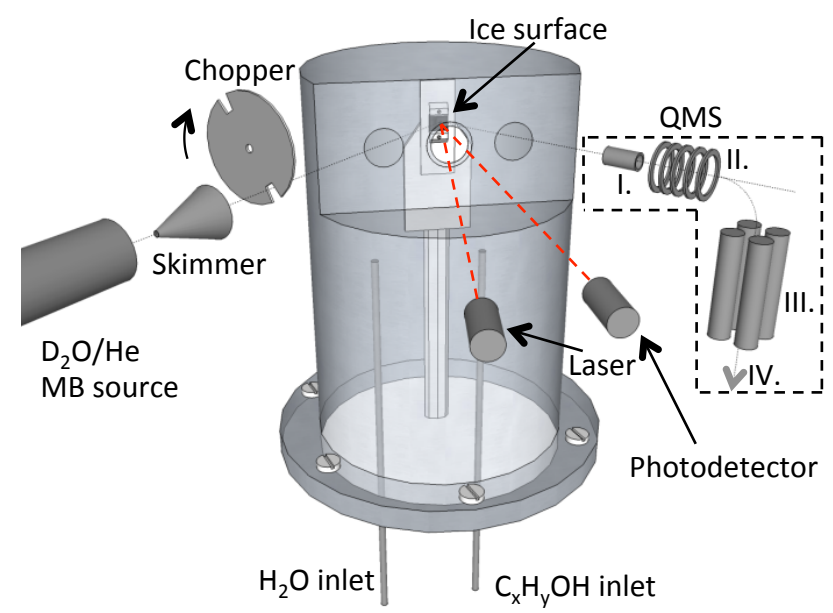

Fig. 1. Schematic view of the inner-workings of the molecular beam apparatus used in the present study. Molecules leaving the surface enter the QMS and are I. ionized before a II. series of lenses focuses and accelerates them through $90^{\circ}$ before entering the III. quadrupole rods, which focus the IV. selected ions onto the detector.

Here we explore water interactions with thin butanol and methanol layers on ice and investigate how these substances alter the water uptake behavior of the ice. The alcohol/ice mixture results are compared with the analogous more simple single species systems. There are fundamental reasons to study the role of organic films at liquid and solid water interfaces - for example to constrain surface accommodation and diffusive processes - and in the atmosphere hydrous aerosols play an important role in global climate and atmospheric chemistry. Thus, we strive to put our work into an atmospheric context and to investigate conditions relevant to the tropical troposphere and lower stratosphere.

\section{Experimental}

\subsection{Apparatus}

The Environmental Molecular Beam (EMB) technique utilizes an apparatus (Kong et al., 2011) that contains atmospheric-analog surfaces that are investigated at a molecular level, at the temperatures and partial water vapour pressures found in the upper troposphere and lower stratosphere. The apparatus is an ultra-high vacuum (UHV) system which utilizes a pulsed gas source to direct a low density beam of molecules towards a surface in a central UHV chamber (Fig. 1). The bare surface at the center of the main UHV chamber is a $12 \times 12 \mathrm{~mm}$ piece of cleaved highly oriented pyrolytic graphite (HOPG, produced by Advanced Ceramics Corp., grade ZYB) that is cleaned between experiments by heating to $500 \mathrm{~K}$. It is surrounded by an environmental chamber with gas inlets positioned to facilitate surface condensation. Within the environmental chamber experimental 
vapour pressures of $\leq 10^{-2}$ mbar can be sustained without dramatically interfering with the propagation of the molecular beam (Kong et al., 2011). The gas inlets are used to introduce condensing species like water that form layers on the temperature controlled graphite surface. In these experiments the molecular beam was a mixture of helium and heavy water $\left(\mathrm{D}_{2} \mathrm{O}\right)$ gases with $\mathrm{D}_{2} \mathrm{O}$ incident kinetic energies of 0.29 $0.33 \mathrm{eV}$. Although the molecules have higher than thermal energies, except for direct scattering the resulting collisions are still expected to be reflective of thermal behavior. The ice surface has been shown to dissipate energy very efficiently due to the phonon spectrum of the lattice, even at much larger incident energies (Bolton et al., 1999; Gibson et al., 2011). This dissipation to surface modes has been observed over wide ranges of temperature, angle of incidence, and for multiple molecular species (e.g., $\mathrm{He}, \mathrm{Ne}, \mathrm{Ar}, \mathrm{HCl}, \mathrm{H}_{2} \mathrm{O}$, Bolton et al., 1999; Andersson et al., 2000; Gibson et al., 2011). Thus, we do not anticipate mechanical penetration or secondary fragmentation from the surface due to the intensity of the impact.

Using $\mathrm{D}_{2} \mathrm{O}$ increases the signal-to-noise ratio by distinguishing the beam $\mathrm{D}_{2} \mathrm{O}$ from the Millipore deionized water that forms condensed ice. After being generated and passing through a frequency chopper, which modulates the $400 \mu \mathrm{s}$ molecular beam pulses, the beam propagates through a $5 \mathrm{~mm}$ diameter hole into the environmental chamber and impacts the surface at an incident angle of $45^{\circ}$. A rotatable quadrupole mass spectrometer (QMS) can be positioned directly in the beam line to measure the incident flux, or at $45^{\circ}$ from the surface normal to measure the outgoing surface flux that propagates through a second $5 \mathrm{~mm}$ hole. Directly above the surface a glass window allows the reflected intensity from a $0.86 \mathrm{~mW}, 670 \mathrm{~nm}$ diode laser to be continuously monitored.

When investigating ice and alcohol substrates the experimental procedure begins by growing an adlayer on the graphite surface from condensing vapour introduced through the gas inlets. Elastic scattering of He from the surface is efficiently attenuated by adlayers and the effective He cross section scales almost linearly with surface coverage. Thus the He beam serves as a direct probe of the sub-monolayer surface coverage (Poelsema and Comsa, 1989). Additional ice or surfactant layer growth is further monitored using the continuously reflected laser signal, whose attenuation can be interpreted in terms of ice layer morphology and thickness, as has been previously described (Kong et al., 2012). The substrate of interest (ice or ice + alcohol) is grown to a steadystate $\approx 1 \mu \mathrm{m}$ thickness, as detected by the laser light scattering, by optimizing the pressure in the environmental chamber. To limit the beam attenuation, in the present experimental setup, the environmental chamber's equilibrium vapour pressure cannot exceed $10^{-2} \mathrm{mbar}$ (Kong et al., 2011). This constraint effectively fixes the required steady state vapour fluxes and thus upwardly limits the experimental range of temperature.
Once the vapour fluxes have been set to ensure steadystate surface layer thickness, the fluxes from the surface are monitored using the QMS. The $\mathrm{D}_{2} \mathrm{O}$ flux from the sample surface enters the differentially pumped QMS and ionized particle counts are processed and output by a multichannel scaler with a $\Delta t=10 \mu$ s dwell time. The result is a record of detected time versus ion count that with the known experimental geometry is converted into time-of-flight (TOF) measurements for particles traveling within the plane defined by the beam and surface normal. In addition to measurements of prepared surfaces, scattering from the bare graphite surface is measured at each temperature in order to normalize results between experiments and ensure system performance and consistency. Additionally, the intensity distribution of the incident beam is measured directly by rotating the QMS. This measurement serves as the initial parameter in the quantitative analysis of raw TOF distributions (Sect. 2.2) that are used to determine components of direct scattering and thermal desorption.

The experimental procedure allows for the exploration of many different prepared surfaces. Additionally, properties of adsorbed alcohol layers on ice can be directly compared to earlier experiments which used pure alcohol layers (Thomson et al., 2011).

\subsection{Analysis}

The quantitative analysis of the final TOF intensity distributions relies on a nonlinear least-squares fitting of the measured intensities that accounts for the molecules surface arrival times. In these experiments we assume a combination of inelastic scattering and first-order thermal desorption of $\mathrm{D}_{2} \mathrm{O}$ from the ice/alcohol surfaces. The thermal desorption is modeled with a residence time behavior of the form,

$F_{\text {res }}(t)=C_{1} \exp (-k t)$,

where $C_{1}$ is a fitted scaling factor, $k$ is the fitted desorption rate constant, and $t$ is time. The inelastic scattering distribution is assumed to have the common form (Suter et al., 2006),

$I_{\text {is }}(v(t))=C_{2} v(t)^{4} \exp \left[-\left(\frac{v(t)-\bar{v}}{v_{\text {is }}}\right)^{2}\right]$,

where $C_{2}$ is a second scaling factor, $v(t)$ is the particle velocity calculated from the travel time $t$ and flight path length $l$ between the surface and QMS, $\bar{v}$ represents the peak of the inelastically scattered beam velocities, and $v_{\text {is }}$ is,

$v_{\text {is }}=\sqrt{\frac{2 k_{\mathrm{B}} T_{\mathrm{is}}}{m}}$,

where the temperature $T_{\text {is }}$ is indicative of the temporal spread in the inelastically scattered molecules, $k_{\mathrm{B}}$ is the Boltzmann constant, and $m$ is the molecular mass in kilograms. When 
assuming an inelastic contribution both $\bar{v}$ and $T_{\text {is }}$ are left as free fitting parameters. The flexibility of the algorithm is ensured by the five free parameters, whose best fit values determine a global minimum in the sum of the squared residuals. The confidence intervals of the fitting reflect the shallowness of the minimum and are propagated in the error analysis, as discussed below. When the thermal desorption is fast, with very short surface residence times, as on bare graphite, the decay constant can be forced $k \gg 10^{3} \mathrm{~s}^{-1}$ in order to reduce the number of free parameters and to improve the quality of the regression. This prevents fitting for time constants faster than the experimental time resolution $(\approx 100 \mu \mathrm{s})$ and simplifies the computation.

From the thermal desorption components of the fitting procedure, Arrhenius parameters are calculated from the temperature dependence of the decay constant $k$. Absolute water uptake coefficients $\alpha(T)$ for surface temperatures $T$ are computed from the integrated thermal distributions. Although they are not always interchangeable, in this case because the low density molecular flow dominates the system, the quantity $\alpha(T)$ is equivalently the mass accommodation coefficient and/or the uptake coefficient (Kulmala and Wagner, 2001). That is $\alpha(T)$ represents the absolute fraction of molecules that collide with the surface and are incorporated into the ice.

The thermal distributions are computed by normalizing each thermal desorption integral by the desorption from a contiguously measured bare graphite case. The desorption for the bare case is then linearly scaled by the sticking coefficient $s=0.73 \pm 0.07$ for $\mathrm{D}_{2} \mathrm{O}$ on bare graphite, which was measured experimentally by comparing sticking for molecules with different incident kinetic energies. The value of $s$ was also investigated numerically with classical molecular dynamic simulations of $\mathrm{D}_{2} \mathrm{O}$ scattering from graphite. The calculations were carried out for the $\mathrm{D}_{2} \mathrm{O}$ /graphite system as described in Marković et al. (1999, 2000), using a modified gas-surface potential with improved asymptotic behaviour. Water molecules were treated as rigid with the potential smoothly truncated at $15 \AA$. Such molecules with incident kinetic energy, $\mathrm{KE}_{\mathrm{D}_{2} \mathrm{O}}=0.32 \mathrm{eV}$, were simulated to impact a $T=180 \mathrm{~K}$ graphite surface at an incident angle $\theta_{i}=45^{\circ}$. The probability of more than a single surface collision was $0.77 \pm 0.01$, and the probability of more than five collisions was $0.74 \pm 0.01$, both in good agreement with the experimentally measured value. Using this sticking coefficient $s$ as a scaling parameter $\alpha(T)$ is easily computed as,

$\alpha(T)=1-P_{\mathrm{T}}$,

where $P_{\mathrm{T}}=s I_{\mathrm{td}}^{c} / I_{\mathrm{td}}^{b}$ is the absolute trapping probability calculated from the integrated thermal desorption in the bare $I_{\mathrm{td}}^{b}$ and ice covered $I_{\mathrm{td}}^{c}$ cases. In each case an error estimate is calculated from the range of integral values based on the $95 \%$ confidence intervals for the fitting parameters that contribute to the thermal decay function. The final error is based on propagating the error of each integral and the uncertainty in $s$. This provides the measurement uncertainty (see, Figs. 3 and 5) but does not necessarily account for the reproducibility between differently prepared surfaces. We also note that, although a priori we cannot know the functional dependence of $\alpha$, we write $\alpha(T)$ to illustrate that it may have some temperature dependence.

The calculation of the absolute trapping probability is necessarily constrained by the time scale of the experiment $(10 \mathrm{~ms})$. A second independent analysis is used to compute uptake coefficients at long times. This kinetic analysis is best understood by modeling the environmental chamber and surface as a reservoir for $\mathrm{H}_{2} \mathrm{O}$ molecules whose number $N$ changes in time in proportion to changes in the incoming and outgoing fluxes. Thus,

$$
\frac{\mathrm{d} N}{\mathrm{~d} t}=F_{\mathrm{in}}+F_{\mathrm{des}}-a N-b \alpha(T) N,
$$

where $F_{\text {in }}$ is a vapour source term, $F_{\text {des }}$ represents zeroth order desorption from the surface, $\alpha(T)$ remains the surface uptake coefficient, and $a$ and $b$ are constants that describe the vapour loss rate from the environmental chamber to the surrounding UHV chamber and from the vapour to the ice surface respectively. The surface desorption $F_{\mathrm{des}}=k N_{s}$ is a product of the desorption rate constant and the number of molecules on the surface. Vapour outflow from the environmental chamber to the surrounding vacuum chamber $a N$ is assumed to be linearly proportional to the total number of molecules. For comparison with experiments the key parameter is the physical observable, pressure $P \propto N / V$, which is simply the scaled number of molecules. Experimentally there are two situations when convenient measurements can be made and the system is in steady state $\mathrm{d} P / \mathrm{d} t=\mathrm{d} N / \mathrm{d} t=0$. The first is when a constant ice thickness is maintained. In this case the adsorption and desorption rates of molecules from the surface are by definition equivalent as are the inflow to and outflow from the environmental chamber. Thus,

$N_{1}=\frac{F_{\mathrm{des}}}{\alpha b}$.

Likewise, if the water input flux is set to zero, allowing the surface to evaporate, and for some time a steady state pressure is observed then,

$N_{2}=\frac{F_{\mathrm{des}}}{a+\alpha b}$.

The ratio of these experimentally observed pressures,

$\frac{N_{2 \mathrm{~b}, \mathrm{w}}}{N_{1 \mathrm{~b}, \mathrm{w}}}=\frac{P_{2 \mathrm{~b}, \mathrm{w}}}{P_{1 \mathrm{~b}, \mathrm{w}}}=\frac{b \alpha_{\mathrm{b}, \mathrm{w}}}{a+b \alpha_{\mathrm{b}, \mathrm{w}}}$,

for the butanol covered and pure ice (b,w subscripts, respectively) cases can be used to solve for the relative uptake coefficient $\alpha_{\mathrm{b}}(T)$ in the butanol covered case compared to the 
uptake coefficient on pure water ice $\alpha_{\mathrm{w}}(T)$. Thus,

$$
\frac{\alpha_{\mathrm{b}}(T)}{\alpha_{\mathrm{w}}(T)}=\frac{\frac{P_{1 \mathrm{w}}}{P_{2 \mathrm{w}}}\left(1-\frac{P_{2 \mathrm{w}}}{P_{1 \mathrm{w}}}\right)}{\frac{P_{1 \mathrm{~b}}}{P_{2 \mathrm{~b}}}\left(1-\frac{P_{2 \mathrm{~b}}}{P_{1 \mathrm{~b}}}\right)},
$$

can be calculated directly from experimental measurements of pressure. The value of the uptake coefficient of water on ice is an area of active debate with evidence suggesting that $\alpha_{\mathrm{w}}<1$ (Chaix et al., 1998; Marek and Straub, 2001; Pratte et al., 2006; Davidovits et al., 2006). However, for pure ice surfaces at our ms experimental timescales we observe complete trapping of water molecules, and therefore assume $\alpha_{\mathrm{w}}=1$ for consistency, and to calculate an upper bound for $\alpha_{\mathrm{b}}(T)$. The experimental $\mathrm{H}_{2} \mathrm{O}$ vapour pressures $P_{1 \mathrm{~b}, \mathrm{w}}$ and $P_{2} \mathrm{~b}, \mathrm{w}$ are measured using the QMS with an uncertainty that is propagated through Eq. (9) to determine the confidence intervals in $\alpha_{\mathrm{b}}$. The shortcoming of this technique is that each pressure in Eq. (9) must be distinct from the background vapour pressure of the chamber. For butanol covered ice this requirement limits the accessible temperature range to $185 \mathrm{~K}$ and above. However, taken together the two independent methods of determining mass accommodation coefficients provide a temporal bracket for water uptake by butanol covered ice surfaces.

From the inelastic scattering distribution the average kinetic energy $\left(\mathrm{KE}=m v^{2} / 2\right)$ of the scattered molecules is calculated from the ensemble of inelastic velocities,

$$
<v^{2}>=v_{\mathrm{o}}^{2} \frac{\sum_{i} I_{i} / i^{2}}{\sum_{i} I_{i}},
$$

where $v_{\mathrm{o}}=l / \Delta t$ is a unit velocity and $I_{i}$ represents the count intensity measured at the QMS at each measurement interval $i$.

\section{Results}

Molecular beam experiments were carried out to monitor the scattering of $\mathrm{D}_{2} \mathrm{O}$ from methanol and butanol covered ice surfaces. These results are compared to scattering from three other types of surfaces, (i) bare crystalline graphite which was used as the underlying substrate in all experiments, (ii) pure water ice surfaces, and (iii) pure alcohol surfaces.

\subsection{Water interactions with methanol-covered ice}

The interaction of $\mathrm{D}_{2} \mathrm{O}$ with methanol-covered ice was investigated in five degree increments for temperatures from $170 \mathrm{~K}$ to $190 \mathrm{~K}$. The spatial consistency of the adsorbed methanol monolayers was determined by applying a range of methanol partial pressures at $185 \mathrm{~K}$. Stable methanol monolayers were created and maintained at partial pressures, $p=0.09 p_{0}$ where $p_{0}$ represents the bulk equilibrium vapour pressure measured over $\mu \mathrm{m}$ thick methanol multilayers. Monolayer coverage was experimentally verified at $185 \mathrm{~K}$ by repeating experiments at $p / 10$ and $p / 100$. In each case the scattering was unchanged, confirming complete methanol coverage. The partial pressure $p=0.09 p_{0}$ represents a range of absolute pressure from $2 \times 10^{-5}-8 \times 10^{-4} \mathrm{mbar}$ that was calculated using the data and parameterization given by Schmeling and Strey (1983) for $p_{0}$. A comparison of these pressures with linear extrapolations of previously published Langmuir constants for methanol (Winkler et al., 2002), results in predicted fractional coverages between 0.6 and 0.98 . These values are somewhat low, likely as a result of a linear extrapolation error, but confirm that significantly less coverage than a monolayer is unlikely. These tests and the supporting observations and modeling of (Jedlovszky et al., 2006), which demonstrate that monolayer methanol on ice is significantly more stable than bulk methanol, provide convincing evidence that methanol monolayer coverages are maintained over the entire experimental temperature range.

The uniqueness of the methanol covered ice surface is clearly seen in Fig. 2 where TOF distributions for the various surfaces at $185 \mathrm{~K}$ are directly compared. As expected the most intense $\mathrm{D}_{2} \mathrm{O}$ signal comes from the bare graphite surface, due to the weak water-graphite interaction (Marković et al., 1999, 2000), which results in a high probability for inelastic scattering of hyperthermal $(0.3 \mathrm{eV}) \mathrm{D}_{2} \mathrm{O}$ molecules. A pure layer of methanol is less efficient at inelastically scattering the molecules and increases the fraction of trapped molecules. The extended tail of the distribution (brown line, Fig. 2) is indicative of thermally activated desorption from the surface, that has been observed to be temperature dependent (Thomson et al., 2011). In the case of methanol covered ice $\mathrm{D}_{2} \mathrm{O}$ is obviously efficiently trapped, resulting in a very small TOF peak that is mostly due to inelastic scattering (lower panel, Fig. 2). However, even this small peak is clearly distinguishable from the pure ice case, where no outgoing flux is measured above the background levels. Thus on the $10 \mathrm{~ms}$ time scale $\mathrm{D}_{2} \mathrm{O}$ impinging on pure ice is completely incorporated into the solid.

The isotopic exchange of hydrogen and deuterium atoms was considered as a possible secondary sink of $\mathrm{D}_{2} \mathrm{O}$, but the absence of observable HDO limits that possibility to less than $1 \%$ of incident molecules, due to the threshold of experimental noise.

In contrast with pure methanol no temperature dependence of the desorption rates is observed for the methanol covered ice (cf. Thomson et al., 2011). Likewise over the 170-190 K temperature range no significant trend in trapping-desorption fraction exists (Fig. 3). The $\mathrm{D}_{2} \mathrm{O}$ that undergoes trappingdesorption on the methanol covered ice surfaces is minimal and never exceeds $5 \%$ of the incident $\mathrm{D}_{2} \mathrm{O}$. In fact, for low temperatures it is indistinguishable from the background. This was confirmed by simplifying the TOF fitting algorithm to fit a single inelastic peak to the distributions. In the low temperature cases for methanol on ice the difference between 


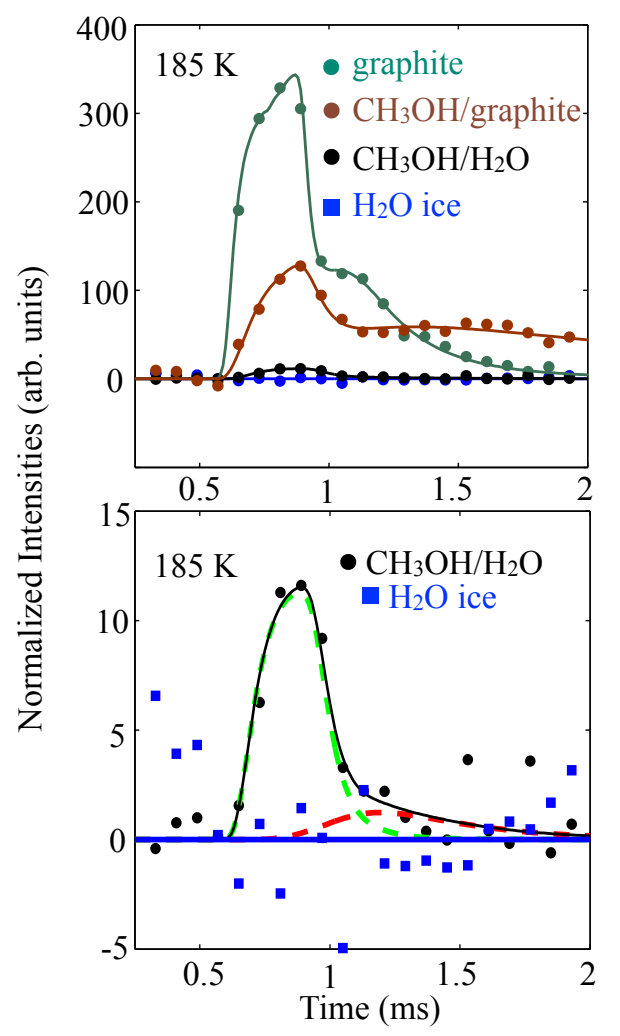

Fig. 2. Time-of-flight distributions for $\mathrm{D}_{2} \mathrm{O}$ scattering from different surfaces at $185 \mathrm{~K}$, normalized for variations in incident beam intensity and data collection time. In the upper panel the best nonlinear fitting curves overlie the background corrected and eightpoint averaged data. The lower panel is a zoomed-in-view of the curves for the bare (blue) and methanol coated (black) ice, where for the methanol coated case the complete non-linear fit is also decomposed into its inelastic scattering (dotted green curve) and thermal desorption (dotted red curve) components. No $\mathrm{D}_{2} \mathrm{O}$ desorption is observed from the pure ice.

the sum of the residuals for the single and double peak fitting procedures was typically less than one percent. Thus in these cases any small thermal-desorption contribution to the distributions is within the noise of the experimental measurements. This is an important finding because it suggests that unless the impinging $\mathrm{D}_{2} \mathrm{O}$ molecules are directly scattered from methanol their surface residence times are generally sufficient for them to become incorporated into the ice structure.

The average final kinetic energy of directly scattered molecules from methanol covered ice surfaces was $19 \%$ of the incident kinetic energy $(0.33 \mathrm{eV})$, in near agreement with both the scattering from pure methanol monolayers (Thomson et al., 2011) and scattering from butanol covered ice (Sect. 3.2). The efficient energy transfer to surface modes favors trapping of $\mathrm{D}_{2} \mathrm{O}$. Under thermal conditions incident kinetic energies are more than an order of magnitude less than in these experiments. Thus under thermal conditions we

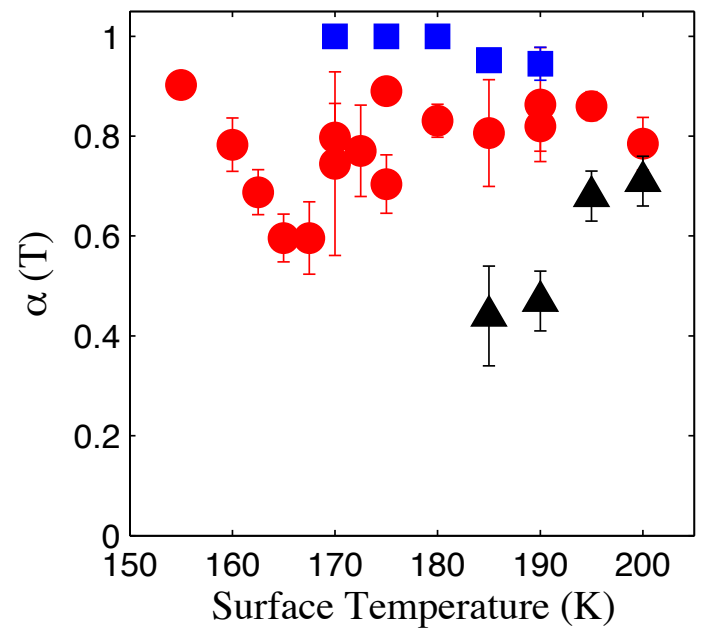

Fig. 3. The $\mathrm{D}_{2} \mathrm{O}$ uptake coefficient $\alpha(T)$ calculated with TOF measurements for methanol covered ice (blue squares), butanol covered ice (red circles) and $\mathrm{H}_{2} \mathrm{O}$ uptake for the butanol covered ice at long times using bulk vapour pressure measurements (black triangles). Where not visible the error bars are subsumed by the data points. Section 2.2 describes the error analysis for the blue and red points, while the error of the black points is calculated directly by propagating the measurement uncertainty.

expect $\mathrm{D}_{2} \mathrm{O}$ collisions with methanol covered ice will result in a trapping probability of unity.

We conclude that the methanol monolayer on ice does not influence water uptake within the temperature range investigated. In contrast to the current experiments with hyperthermal incident velocities that give rise to minor inelastic scattering, water will undergo efficient uptake under thermal conditions.

\subsection{Water interactions with butanol-covered ice}

Water $\left(\mathrm{D}_{2} \mathrm{O}\right)$ scattering from butanol covered ice was investigated for surface temperatures from 155 to $200 \mathrm{~K}$ using the same technique that was used for the methanol covered ice surfaces. Isotopic exchange and HDO formation was again eliminated as a possible sink of $\mathrm{D}_{2} \mathrm{O}$. The behavior of the butanol surfaces was observed to be quite distinct from the behavior of methanol. In general, water molecules colliding with butanol coated ice surfaces directly scatter and thermally desorb more efficiently than from the methanol coated surfaces (Fig. 4). Unlike desorption from methanol coated ice, desorption from butanol coated ice has an observable temperature dependent behavior.

At low temperatures the $\mathrm{D}_{2} \mathrm{O}$ desorption kinetics have a relatively long decay constant when compared to higher temperatures (Fig. 4) or to methanol coated ice (cf. Fig. 2). The result is temperature dependent behavior for $T \leq 175 \mathrm{~K}$ (Fig. 5), that can be fit in an Arrhenius-type manner, wherein the desorption rate constant $k$ depends on the surface temperature $T$ and an activation energy $E_{\mathrm{a}}, k=A e^{-E_{\mathrm{a}} / k_{\mathrm{B}} T}$. 


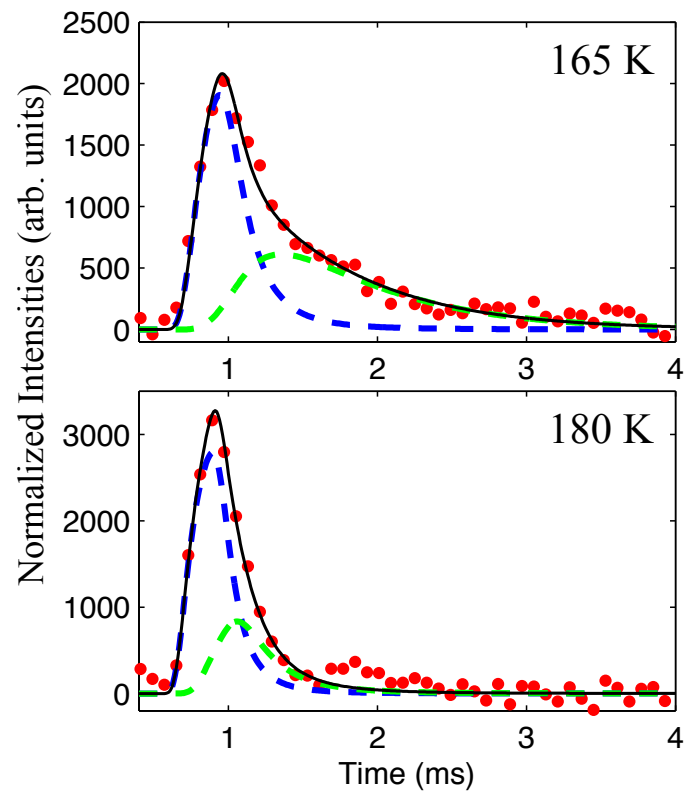

Fig. 4. Time-of-flight distributions for $\mathrm{D}_{2} \mathrm{O}$ scattering and desorbing from butanol covered ice surfaces. The black, blue, and green curves show the total, inelastic, and thermal desorption components of the non-linear fitting described in the text, and overlie a threepoint smoothing of the data.

Using the Arrhenius formulation, a linear least-squares fitting of the temperature dependence of thermal desorption between 155 and $175 \mathrm{~K}$ is found to have an activation energy $E_{\mathrm{a}}=0.1 \pm 0.1 \mathrm{eV}$ and $A=2.1 \times 10^{6 \pm 3} \mathrm{~s}^{-1}$ (Fig. 5). The observed temperature dependence is weak with considerable uncertainty due to the desorption rate confidence intervals and the scatter in the data. The Arrhenius parameter estimates yield an estimated surface residence time of $\approx 100 \mu \mathrm{s}$ at $200 \mathrm{~K}$. This illustrates that the trend of thermal activation may continue to higher, tropospherically relevant, temperatures but will result in high rate constants $\left(k \geq 10^{4} \mathrm{~s}^{-1}\right)$ and therefore short surface lifetimes, at the limit of our experimental resolution.

Water interacting with pure butanol monolayers on graphite did not exhibit temperature dependent desorption behavior, rather the thermally activated $\mathrm{D}_{2} \mathrm{O}$ desorption from butanol, within the experimental range of temperature, is always faster $\left(k \gg 10^{4} \mathrm{~s}^{-1}\right)$ than the experimental time resolution of $\approx 10-100 \mu \mathrm{s}$. This is different from the pure methanol system, for which we have previously observed that desorbing water obeys Arrhenius-type behavior for temperatures from 170 to $190 \mathrm{~K}\left(E_{\mathrm{a}}=0.47 \pm 0.11 \mathrm{eV}, A=4.6 \times\right.$ $10^{15 \pm 3} \mathrm{~s}^{-1}$, Thomson et al., 2011). The differences between the alcohol coverages can be straightforwardly interpreted as a competition between $\mathrm{D}_{2} \mathrm{O}$ desorption and diffusion through the surfactant layers (Sect. 4).

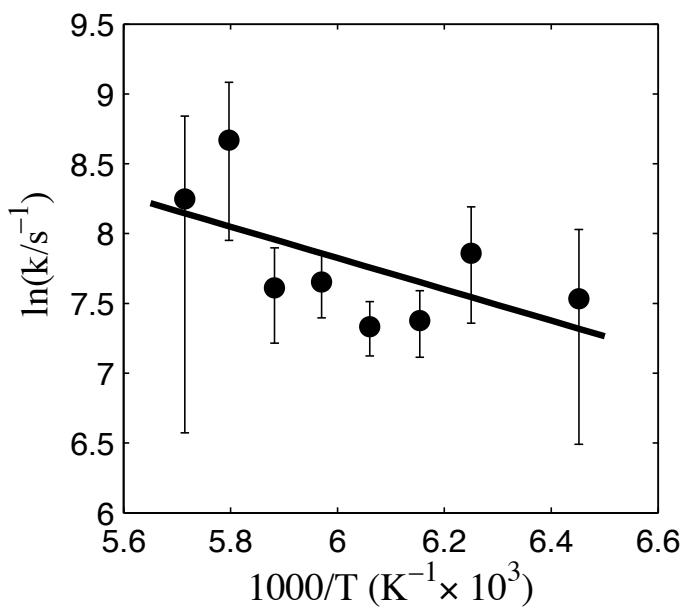

Fig. 5. Arrhenius plot of the rate coefficients for desorption of $\mathrm{D}_{2} \mathrm{O}$ from butanol covered ice for $T=155 \mathrm{~K}$ to $175 \mathrm{~K}$. At higher temperatures the decay is too fast for the experimental resolution $\left(k \gg 10^{4} \mathrm{~s}^{-1}\right)$. The solid line is a linear least-squares fit to all of the points with a slope corresponding to $E_{\mathrm{a}}=0.1 \pm 0.1 \mathrm{eV}$ and a preexponential factor $A=2.08 \times 10^{6 \pm 3} \mathrm{~s}^{-1}$.

In Fig. 3 the uptake coefficients $\alpha(T)$ of $\mathrm{D}_{2} \mathrm{O}$ by the methanol and butanol covered ice surfaces are plotted as a function of temperature. The absolute $\mathrm{D}_{2} \mathrm{O}$ trapping probabilities are calculated and converted to water uptake coefficients using the techniques described in Sect. 2.2. The figure illustrates that from $155-200 \mathrm{~K}$ the water uptake of butanol covered ice has no clear temperature dependence. From the TOF distributions we observe that over the entire temperature range, $60 \%$ to $90 \%$, with an average of $78 \%$, of the incident $\mathrm{D}_{2} \mathrm{O}$ is quickly incorporated into the butanol covered ice. At longer time scales the steady state mass accommodation coefficient of $\mathrm{H}_{2} \mathrm{O}$ is slightly lower $(0.45-0.70)$. Thus, the residence time of the water is substantially but not entirely captured by the measured experimental decay using the TOF technique.

Figure 3 shows temperature dependent uptake at $T \leq$ $170 \mathrm{~K}$, which also coincides with the temperature range in Fig. 5 for Arrhenius-type thermally activated desorption. A change from temperature dependent to independent behavior may be indicative of configurational changes within the thin butanol layer on ice.

As computed from the inelastic scattering distributions (Sect. 2.2) the final kinetic energy (with $95 \%$ confidence intervals) of the scattered molecules from butanol covered ice surfaces was $22 \pm 2 \%$ of the incident kinetic energy $(0.30 \pm 0.03 \mathrm{eV})$, independent of temperature.

Collectively, the results demonstrate that although butanol layers are much stronger barriers to water uptake than methanol they remain generally quite permeable to water transport. 


\section{Discussion and atmospheric implications}

In an attempt to better understand the unique differences in the characteristics of butanol and methanol covered ice surfaces we propose a simple explanation for $\mathrm{D}_{2} \mathrm{O}$ permeating each alcohol covered surface. In an idealized view of the ice/monolayer-alcohol/gas system, water molecules can be found in three locations: incorporated into the ice, adsorbed on the alcohol, or in the gas. Incident $\mathrm{D}_{2} \mathrm{O}$ molecules that stick to the surface, undergo a random walk until they either penetrate the alcohol layer, or are thermally re-desorbed into the gas. Previous work has suggested that long-chain surfactants form well ordered impermeable domains separated by regions of more disorder where "accessible surface" exists (Barnes, 1997). For shorter chain alcohols this argument is supported by simulations that show a monolayer butanol structure is mutually beneficial for the alcohol and water due to excess hydrogen bond matching at the interface, that results in orientational ordering but compositional heterogeneity (Chen et al., 2002). Lawrence et al. (2005) used this idea to explain their observation of no evaporative impediment for $\mathrm{D}_{2} \mathrm{O}$ leaving $\approx 80 \%$ butanol covered sulfuric acid. They provide a Monte Carlo visualization of a butanol/water interface (see Fig. 10 in Lawrence et al., 2005) and argue that high mobility and density fluctuations in the butanol layer readily allow for evaporation. Our experimental temperature range $\leq 200 \mathrm{~K}$ and monolayer coverages, are distinctly different from the Chen et al. (2002) simulations at 298.15 K, and the Lawrence et al. (2005) experiments with sub-monolayer films. In our case solid ice is completely covered by the alcohol monolayers, yet still the transport rate of $\mathrm{D}_{2} \mathrm{O}$ from the top of the film to the subsurface ice outstrips the rate of desorption allowing nearly all of the $\mathrm{D}_{2} \mathrm{O}$ to quickly penetrate the alcohols. The kinetic time scales and thus the rate of diffusion scale with the size of the aliphatic molecules and regulate how quickly water permeates the alcohol layer to interact with the underlying ice, whose uptake coefficient is assumed to be unity. Transport through the methanol layer is fast relative to butanol, allowing almost all incident water to permeate the methanol film and adhere to the ice layer. Hindered diffusion through the butanol layer still allows a substantial fraction of the water to pass through. However, the residence time on the surface means that some of the $\mathrm{D}_{2} \mathrm{O}$ is reemitted by thermal desorption. The specific temperature dependencies that result are likely due to the molecular bond structures formed at the alcohol-ice interface and/or within the pure alcohol layers. For example, observations suggest that water molecules bridge methanol chains, forming ring structures in liquid mixtures (Guo et al., 2003). Conversely, on ice surfaces simulations have shown that submonolayer methanol forms two hydrogen bonds with the surface water molecules. At full monolayer coverage the methanol-methanol interactions become stronger and half of the $\mathrm{CH}_{3} \mathrm{OH}$ molecules form one hydrogen bond with water and another with a neighboring methanol (Jedlovszky et al.,
2006). Clearly, in this configuration impinging water can access the ice surface. In the case of 1-butanol simulated monolayers are well-organized but include density fluctuations that lead the butanol to have more conformational disorder than molecules with longer alkyl tails, like hexanol (Chen et al., 2002).

Putting these results in the context of previous studies supports the conclusion that surface active organic compounds affect water adsorption and desorption processes on hydrous atmospheric aerosol particles with an intensity that is related to the size of the surfactant molecules. Previously work has focused on longer chain surfactants like fatty acids and alcohols with more than ten carbon molecules, and their evaporative retardation at higher temperatures, $\geq 273 \mathrm{~K}$ (La Mer et al., 1964; Gill et al., 1983). Such studies have used evaporation rate measurements to calculate evaporative resistances which are observed to increase with carbon chain length (La Mer et al., 1964; Barnes, 1997, 2008). The dependence of evaporative resistance on molecular size is indicative of similar uptake coefficient dependencies but they are not necessarily direct analogues because the relationship between evaporation and accommodation is complex and sensitive to the microscopic reversibility of the processes (Cappa et al., 2005). However, other direct studies of uptake by liquid and solid water surfaces show similar results. Glass et al. (2006) found that 1-hexanol films on $56 \mathrm{wt} \%$ sulfuric acid impede $\mathrm{D}_{2} \mathrm{O}$ transport at $213 \mathrm{~K}$ but the effect vanishes for higher acidity solutions. A study of 1-butanol films under similar experimental conditions found no effect on the water loss from 60 to $68 \mathrm{wt} \% \mathrm{D}_{2} \mathrm{SO}_{4}$ solutions (Lawrence et al., 2005). Conversely, molecular dynamics simulations have shown a threefold reduction in the rate of water condensation through butanol films onto liquid water (Gilde et al., 2009). Still other EMB studies showed that short chain alcohols have effects on the nucleation and morphology of growing ice that likely stem from changes in the molecular kinetics (Kong et al., 2012).

There are several cold, cloud forming regions within the atmosphere. The tropopause has an average temperature of $\approx 215 \mathrm{~K}$ but is much colder in the tropics $(\gtrsim 185 \mathrm{~K})$ and during polar nighttime $(\approx 195 \mathrm{~K})$ when polar-stratospheric clouds form. Thus, our experimental results illustrate that even relatively simple volatile organic molecular layers can have distinct effects on ice surfaces at temperatures relevant for the atmosphere. However, the direct application of our experimental results to the atmosphere must be tempered by a discussion of the important differences between the idealized experimental conditions and the real atmosphere. First, in the atmosphere the thermal gas kinetic energies are quite low in comparison with this study, which uses a high energy beam of molecules. Under environmental conditions the energy for direct scattering is low, and the expected molecular behavior can be modeled entirely by trapping followed by either desorption or diffusion through the alcohol layer and incorporation into the bulk. A further distinction between 
the experimental and real-atmosphere settings is the relatively high alcohol gas pressure that is used experimentally to ensure complete mono-molecular layer coverage throughout the experiments. While this gas pressure is higher than encountered in the atmosphere, our measurements are meant to provide a bounding estimate for complete single species alcohol layers. In the atmosphere ice particles will be exposed to multiple species of surfactants simultaneously, including other low vapour pressure compounds similar to those studied here. The resulting resistance of such multi-component films to water transport will be a convolution of the resistances of the surfactant species (McNeill et al., 2006). Thus, although for ice clouds and/or ice cloud modeling the consequences of pure methanol and butanol surfactants will be small, from a fundamental perspective we do observe systematic physical effects.

In the atmosphere molecular surfactants that limit water uptake may contribute macroscopically to changes in cloud particle size and thus potentially affect secondary ice processes and cloud lifetime, both of which have potential impacts on the water cycle and climate. Organic molecules are ubiquitous throughout the atmosphere (Hudson et al., 2002), and may participate in a range of processes, such as chemical scavenging (Sokolov and Abbatt, 2002), in addition to physically affecting ice particles. Furthermore, when a surfactant is present transport pathways must be considered, because changes in residence time coincide with changes in the potential of ice particles to act as chemical reactors (Park et al., 2009). Indeed, condensed phase surfactants are often more likely to participate in photochemistry than their gaseous phase counterparts, and can further benefit from enhanced lifetimes, if for example the scavenging of small droplets or ice particles by larger particles is reduced by organic layers (Gill et al., 1983).

Measurements of water and surfactant molecule interactions remain of importance for building a complete picture of real atmospheric processes. Such particle and molecular scale processes are poorly integrated into larger cloud and climate scale models, that generally have poorly constrained ice surface interaction schemes (Marécal et al., 2010). Furthermore the bundling of complex microphysical chemistry into parameters like surface tension can result in errors from oversimplification (Prisle et al., 2012). Thus it remains of continuing importance to capture the fundamental interactions that occur at the dynamic ice interfaces found under atmospheric conditions.

\section{Conclusions}

In this study we have quantified the effects of methanol and butanol on water uptake by ice, and by analogy sublimation, at upper tropospheric conditions. Collisions between water molecules and alcohol covered ice layers result in efficient surface trapping, with a small fraction of hyperthermal in- cident molecules inelastically scattered. Escaping molecules from both methanol and butanol covered ice retain approximately $20 \%$ of their incident kinetic energies, indicating an efficient energy transfer to surface modes. Methanol is observed to have very little effect on water transport at the ice interface, while on average butanol reduces water uptake by ice by $20 \%$. For both surfactants the absolute uptake of water by ice appears to be independent of temperature. However, the residence time of water on the butanol surface decays with temperature in a thermally activated manner, suggesting molecular residence times of tens of microseconds for temperatures of $200 \mathrm{~K}$ and greater. The distinctly different ice surface effects that these relatively simple surfactant molecules have suggests that larger volatile organic molecules will have even more pronounced impermeability. Thus, in addition to changing growth morphology (Kong et al., 2012), in the extreme such molecular layers may have the effect of making hydrophilic ice particles hydrophobic. This is an active area of scientific investigation where continued experiments can illuminate important microphysical chemistry for the benefit of fundamental studies, molecular dynamical modelers, and cloud and climate modelers.

Acknowledgements. This work is supported by the Swedish Research Council, the University of Gothenburg, and the Nordic Top-Level Research Initiative CRAICC. PP thanks the WennerGren Foundation for providing funding for an extended stay at the University of Gothenburg.

Edited by: M. Boy

\section{References}

Andersson, P. U., Någård, M. B., Bolton, K., Svanberg, M., and Pettersson, J. B. C.: Dynamics of argon collisions with water ice: Molecular beam experiments and molecular dynamics simulations, J. Phys. Chem. A, 104, 2681-2688, 2000.

Barnes, G. T.: Permeation through monolayers, Colloid, Surface A, 126, 149-158, 1997.

Barnes, G. T.: The potential for monolayers to reduce the evaporation of water from large water storages, Agr. Water Manage., 95, 339-353, doi:10.1016/j.agwat.2007.12.003, 2008.

Bartels-Rausch, T., Bergeron, V., Cartwright, J. H. E., Escribano, R., Finney, J. L., Grothe, H., Gutiérrez, P. J., Haapala, J., Kuhs, W. F., Pettersson, J. B. C., Price, S. D., Sainz-Díaz, C. I., Stokes, D. J., Strazzulla, G., Thomson, E. S., Trinks, H., and Uras-Aytemiz, N.: Ice structures, patterns, and processes: a view across the icefields, Rev. Mod. Phys., 84, 885-944, doi:10.1103/RevModPhys.84.885, 2012.

Bolton, K., Svanberg, M., and Pettersson, J. B. C.: Classical trajectory study of argon-ice collision dynamics, J. Chem. Phys., 110, 5380-5391, doi:10.1063/1.478433, 1999.

Cappa, C. D., Drisdell, W. S., Smith, J. D., Saykally, R. J., and Cohen, R. C.: Isotope fractionation of water during evaporation without condensation, J. Phys. Chem. B, 109, 24391-24400, doi:10.1021/jp0539066, 2005. 
Chaix, L., van den Bergh, H., and Rossi, M. J.: Real-Time Kinetic Measurements of the Condensation and Evaporation of $\mathrm{D}_{2} \mathrm{O}$ Molecules on Ice at $140 \mathrm{~K}<T<220 \mathrm{~K}$, J. Phys. Chem. A, 102, 10300-10309, doi:10.1021/jp983050n, 1998.

Chen, B., Siepmann, J. I., and Klein, M. L.: Vapor-liquid interfacial properties of mutually saturated water/1-butanol solutions, J. Am. Chem. Soc., 124, 12232-12237, doi:10.1021/ja027130n, 2002.

Comstock, J. M., Lin, R.-F., Starr, D. O., and Yang, P.: Understanding ice supersaturation, particle growth, and number concentration in cirrus clouds, J. Geophys. Res.-Atmos., 113, D23211, doi:10.1029/2008JD010332, 2008.

Davidovits, P., Kolb, C. E., Williams, L. R., Jayne, J. T., and Worsnop, D. R.: Mass accommodation and chemical reactions at gas-liquid interfaces, Chem. Rev., 106, 1323-1354, doi:10.1021/cr040366k, 2006.

Dixit, S., Crain, J., Poon, W. C. K., Finney, J. L., and Soper, A. K.: Molecular segregation observed in a concentrated alcohol-water solution, Nature, 416, 829-832, 2002.

Dougan, L., Bates, S. P., Hargreaves, R., Fox, J. P., Crain, J., Finney, J. L., Reat, V., and Soper, A. K.: Methanol-water solutions: a bi-percolating liquid mixture, J. Chem. Phys., 121, 64566462, doi:10.1063/1.1789951, 2004.

Eliasson, S., Buehler, S. A., Milz, M., Eriksson, P., and John, V. O.: Assessing observed and modelled spatial distributions of ice water path using satellite data, Atmos. Chem. Phys., 11, 375-391, doi:10.5194/acp-11-375-2011, 2011.

Gibson, K. D., Killelea, D. R., Yuan, H., Becker, J. S., and Sibener, S. J.: Determination of the sticking coefficient and scattering dynamics of water on ice using molecular beam techniques, Journal of Chemical Physics, 134, 034703, doi:10.1063/1.3528116, 2011.

Gilde, A., Siladke, N., and Lawrence, C. P.: Molecular dynamics simulations of water transport through butanol films, J. Phys. Chem. A, 113, 8586-8590, doi:10.1021/jp9026699, 2009.

Gill, P. S., Graedel, T. E., and Weschler, C. J.: Organic films on atmospheric aerosol-particles, fog droplets, cloud droplets, raindrops, and snowflakes, Rev. Geophys., 21, 903-920, 1983.

Glass, S. V., Park, S. C., and Nathanson, G. M.: Evaporation of water and uptake of $\mathrm{HCl}$ and $\mathrm{HBr}$ through hexanol films at the surface of supercooled sulfuric acid, J. Phys. Chem. A, 110, 75937601, doi:10.1021/jp057260t, 2006.

Guo, J. H., Luo, Y., Augustsson, A., Kashtanov, S., Rubensson, J. E., Shuh, D. K., Agren, H., and Nordgren, J.: Molecular structure of alcohol-water mixtures, Phys. Rev. Lett., 91, 157401, doi:10.1103/PhysRevLett.91.157401, 2003.

Hallquist, M., Wenger, J. C., Baltensperger, U., Rudich, Y., Simpson, D., Claeys, M., Dommen, J., Donahue, N. M., George, C., Goldstein, A. H., Hamilton, J. F., Herrmann, H., Hoffmann, T., Iinuma, Y., Jang, M., Jenkin, M. E., Jimenez, J. L., KiendlerScharr, A., Maenhaut, W., McFiggans, G., Mentel, Th. F., Monod, A., Prévôt, A. S. H., Seinfeld, J. H., Surratt, J. D., Szmigielski, R., and Wildt, J.: The formation, properties and impact of secondary organic aerosol: current and emerging issues, Atmos. Chem. Phys., 9, 5155-5236, doi:10.5194/acp-9-51552009, 2009.

Hoose, C., Kristjansson, J. E., Chen, J.-P., and Hazra, A.: A classical-theory-based parameterization of heterogeneous ice nucleation by mineral dust, soot, and biological particles in a global climate model, J. Atmos. Sci., 67, 2483-2503, doi:10.1175/2010JAS3425.1, 2010.

Hudson, P. K., Zondlo, M. A., and Tolbert, M. A.: The interaction of methanol, acetone, and acetaldehyde with ice and nitric aciddoped ice: implications for cirrus clouds, J. Phys. Chem. A, 106, 2882-2888, doi:10.1021/jp012718m, 2002.

Jedlovszky, P., Partay, L., Hoang, P. N. M., Picaud, S., von Hessberg, P., and Crowley, J. N.: Determination of the adsorption isotherm of methanol on the surface of ice, an experimental and Grand Canonical Monte Carlo simulation study, J. Am. Chem. Soc., 128, 15300-15309, doi:10.1021/ja065553+, 2006.

Kong, X., Andersson, P. U., Marković, N., and Pettersson, J. B. C.: environmental molecular beam studies of ice surface processes, in: Physics and Chemistry of Ice 2010, edited by: Furukawa, Y., Sazaki, G., Uchida, T., and Watanabe, N., Hokkaido University Press, Sapporo, Japan, 79-88, 2011.

Kong, X., Andersson, P. U., Thomson, E. S., and Pettersson, J. B. C.: Ice formation via deposition mode nucleation on bare and alcohol-covered graphite surfaces, J. Phys. Chem. C, 116, 8964-8974, doi:10.1021/jp212235p, 2012.

Kulmala, M. and Wagner, P. E.: Mass accommodation and uptake coefficients - a quantitative comparison, J. Aerosol Sci., 32, 833841, doi:10.1016/S0021-8502(00)00116-6, 2001.

La Mer, V. K., Aylmore, L. A. G., and Healy, T. W.: Transport of water through monolayers of long-chain n-paraffinic alcohols, J. Colloid Sci., 19, 673-684, 1964.

Lawrence, J. R., Glass, S. V., and Nathanson, G. M.: Evaporation of water through butanol films at the surface of supercooled sulfuric acid, J. Phys. Chem. A, 109, 7449-7457, doi:10.1021/jp050042f, 2005.

Marécal, V., Pirre, M., Rivière, E. D., Pouvesle, N., Crowley, J. N., Freitas, S. R., and Longo, K. M.: Modelling the reversible uptake of chemical species in the gas phase by ice particles formed in a convective cloud, Atmos. Chem. Phys., 10, 4977-5000, doi:10.5194/acp-10-4977-2010, 2010.

Marek, R. and Straub, J.: Analysis of the evaporation coefficient and the condensation coefficient of water, Int. J. Heat Mass Trans., 44, 39-53, 2001.

Marković, N., Andersson, P. U., Någård, M. B., and Pettersson, J. B. C.: Scattering of water from graphite: simulations and experiments, Chem. Phys., 247, 413-430, doi:10.1016/S03010104(99)00233-5, 1999.

Marković, N., Andersson, P. U., Någård, M. B., and Pettersson, J. B. C.: Erratum to "Scattering of water from graphite: simulations and experiments", Chem. Phys., 252, 409-410, doi:10.1016/S0301-0104(99)00324-9, 2000.

McNeill, V. F., Patterson, J., Wolfe, G. M., and Thornton, J. A.: The effect of varying levels of surfactant on the reactive uptake of $\mathrm{N}_{2} \mathrm{O}_{5}$ to aqueous aerosol, Atmos. Chem. Phys., 6, 1635-1644, doi:10.5194/acp-6-1635-2006, 2006.

Möhler, O., Buttner, S., Linke, C., Schnaiter, M., Saathoff, H., Stetzer, O., Wagner, R., Kramer, M., Mangold, A., Ebert, V., and Schurath, U.: Effect of sulfuric acid coating on heterogeneous ice nucleation by soot aerosol particles, J. Geophys. Res.-Atmos., 110, D11210, doi:10.1029/2004JD005169, 2005.

Morishige, K. and Sakamoto, Y.: Melting of n-butanol and npentanol monolayers adsorbed on graphite - effect of molecular length on melting, J. Chem. Phys., 103, 2354-2360, 1995. 
Morrone, J. A., Hasllinger, K. E., and Tuckerman, M. E.: Ab initio molecular dynamics simulation of the structure and proton transport dynamics of methanol-water solutions, J. Phys. Chem. B, 110, 3712-3720, doi:10.1021/jp0554036, 2006.

Murray, B. J. and Bertram, A. K.: Inhibition of solute crystallisation in aqueous $\mathrm{H}^{+}-\mathrm{NH}_{4}^{+}-\mathrm{SO}_{4}^{2-}-\mathrm{H}_{2} \mathrm{O}$ droplets, Phys. Chem. Chem. Phys., 10, 3287-3301, doi:10.1039/b802216j, 2008.

Park, S.-C., Burden, D. K., and Nathanson, G. M.: Surfactant control of gas transport and reactions at the surface of sulfuric acid, Accounts Chem. Res., 42, 379-387, doi:10.1021/ar800172m, 2009.

Poelsema, B. and Comsa, G.: Scattering of Thermal Energy Atoms from Disordered Interfaces, Springer-Verlag, Berlin, 1989.

Pratte, P., van den Bergh, H., and Rossi, M. J.: The kinetics of $\mathrm{H}_{2} \mathrm{O}$ vapor condensation and evaporation on different types of ice in the range 130-210 K, J. Phys. Chem. A, 110, 3042-3058, doi:10.1021/jp053974s, 2006.

Prisle, N. L., Asmi, A., Topping, D., Partanen, A., Romakkaniemi, S., Dal Maso, M., Kulmala, M., Laaksonen, A., Lehtinen, K., McFiggans, G., and Kokkoa, H.: Surfactant effects in global simulations of cloud droplet activation, Geophys. Res. Lett., 39, L05802, doi:10.1029/2011GL050467, 2012.

Schmeling, T. and Strey, R.: Equilibrium vapor pressure measurements for the $\mathrm{n}$-alcohols in the temperature range from $-30^{\circ} \mathrm{C}$ to $+30^{\circ} \mathrm{C}$, Phys. Chem. Chem. Phys., 87, 871-874, 1983.

Singh, H. B., Kanakidou, M., Crutzen, P. J., and Jacob, D. J.: High concentrations and photochemical fate of oxygenated hydrocarbons in the global troposphere, Nature, 378, 50-54, 1995.

Sokolov, O. and Abbatt, J. P. D.: Adsorption to ice of n-alcohols (ethanol to 1-hexanol), acetic acid, and hexanal, J. Phys. Chem. A, 106, 775-782, doi:10.1021/jp013291m, 2002.
Solomon, S., Qin, D., Manning, M., Alley, R. B., Berntsen, T., Bindoff, N. L., Chen, Z., Chidthaisong, A., Gregory, J. M., Hegerl, G. C., Heimann, M., Hewitson, B., Hoskins, B. J., Joos, F., Jouzel, J., Kattsov, V., Lohmann, U., Matsuno, T., Molina, M., Nicholls, N., Overpeck, J., Raga, G., Ramaswamy, V., Ren, J., Rusticucci, M., Somerville, R., Stocker, T. F., Whetton, P., Wood, R. A., and Wratt, D.: Technical Summary, in: Climate Change 2007: The Physical Science Basis. Contribution of Working Group I to the Fourth Assessment Report of the Intergovernmental Panel on Climate Change, edited by: Solomon, S., Qin, D., Manning, M., Chen, Z., Marquis, M., Averyt, K. B., Tignor, M., and Miller, H. L., Cambridge University Press, Cambridge, United Kingdom and New York, NY, USA, 2007.

Soper, A. K., Dougan, L., Crain, J., and Finney, J. L.: Excess entropy in alcohol-water solutions: a simple clustering explanation, J. Phys. Chem. B, 110, 3472-3476, doi:10.1021/jp054556q, 2006.

Souda, R., Kawanowa, H., Kondo, M., and Gotoh, Y.: Hydrogen bonding between water and methanol studied by temperatureprogrammed time-of-flight secondary ion mass spectrometry, J. Chem. Phys., 119, 6194-6200, doi:10.1063/1.1602055, 2003.

Stephenson, R., Stuart, J., and Tabak, M.: Mutual solubility of water and aliphatic-alcohols, J. Chem. Eng. Data, 29, 287-290, 1984.

Suter, M. T., Bolton, K., Andersson, P. U., and Pettersson, J. B.: Argon collisions with amorphous water ice surfaces, Chem. Phys., 326, 281-288, doi:10.1016/j.chemphys.2006.02.012, 2006.

Thomson, E. S., Kong, X., Andersson, P. U., Marković, N., and Pettersson, J. B. C.: Collision dynamics and solvation of water molecules in a liquid methanol film, J. Phys. Chem. Lett., 2, 2174-2178, doi:10.1021/jz200929y, 2011.

Winkler, A. K., Holmes, N. S., and Crowley, J. N.: Interaction of methanol, acetone and formaldehyde with ice surfaces between 198 and 223 K, Phys. Chem. Chem Phys., 4, 5270-5275, doi:10.1039/b206258e, 2002. 